\title{
If it weren't for the bleeding...
}

\author{
Scott M. Bradley, MD
}

From the Department of Pediatric Cardiac Surgery, Medical University of South Carolina, Charleston, SC.

Disclosures: Author has nothing to disclose with regard to commercial support.

Received for publication Dec 24, 2016; accepted for publication Jan 4, 2017; available ahead of print Feb 24, 2017.

Address for reprints: Scott M. Bradley, MD, Pediatric Cardiac Surgery, Medical University of South Carolina,

CSB 424, 96 Jonathan Lucas St, Charleston, SC 29425 (E-mail: bradlesm@musc.edu).

J Thorac Cardiovasc Surg 2017;153:1516-8

$0022-5223 / \$ 36.00$

Copyright $\subset 2017$ by The American Association for Thoracic Surgery

http://dx.doi.org/10.1016/j.jtcvs.2017.01.018

In King of Hearts, his account of the beginnings of open heart surgery, G. Wayne Miller ${ }^{1}$ titled the first chapter "A River of Blood." Bleeding has clearly been a significant issue since the earliest days of congenital heart surgery. Transfusion of blood products goes hand in hand with bleeding, and much is now known about the negative effects of blood product transfusion in our patients. In this issue of the Journal, Gottlieb and Andropoulos ${ }^{2}$ from Texas Children's Hospital provide an expert opinion on coagulation management in congenital heart surgery. Their review is timely, concise, and easily read. It covers the major current topics regarding perioperative bleeding and blood product transfusion. These include the particular challenge of treating post-cardiopulmonary bypass (CPB) coagulopathy after operations in neonates. Several areas merit further comment.

The 1991 publication by Manno and colleagues ${ }^{3}$ from the Children's Hospital of Philadelphia spurred interest in the use of fresh whole blood for pediatric heart surgery. Fresh whole blood was listed by Norwood ${ }^{4}$ as one of the important components of the first successful Norwood procedures for hypoplastic left heart syndrome. Many centers subsequently pursued the availability of fresh whole blood, particularly for use in neonates. The Manno and colleagues ${ }^{3}$ study demonstrated that the use of fresh whole blood ( $<48$ hours old) reduced postoperative blood loss in patients younger than 2 years undergoing complex surgery. The study also found better postoperative platelet function in the patients who received fresh whole blood. This is curious, because whole blood (like packed red blood cells), is stored at $4^{\circ} \mathrm{C}$ when banked for more than 6 hours. Platelet function is known to deteriorate at this temperature, and standard blood bank procedures for platelet concentrates include storage at room temperature. A subsequent article from the Hospital for Sick Children in Toronto lent support to the use of fresh whole blood. ${ }^{5}$ Neonates ( $<1$ month) were randomly assigned to receive either whole blood reconstituted from components less than 48 hours old or standard component therapy. The reconstituted fresh whole blood group had less bleeding, lower inotrope scores, shorter ventilation times, and shorter hospital stays. Several studies

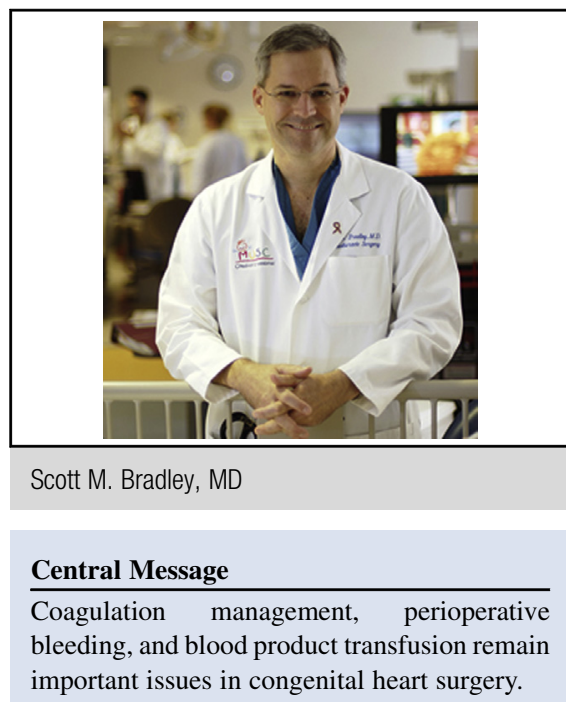

See Article page 1511 .

have also shown that the use of fresh whole blood can decrease overall donor exposures. ${ }^{5-7}$ Many programs, however, have encountered difficulties in obtaining fresh whole blood (or any appropriately screened blood products) within a 48-hour window from donation. For example, in my institution all donated products are processed through the American Red Cross at centers that are out of state (either in Georgia or North Carolina). As a result, the freshest blood available to our blood bank is 4 to 7 days old. Furthermore, all donations are processed into components, so that whole blood of any age is not routinely available. Logistic considerations such as these have limited the availability of fresh whole blood for pediatric cardiac surgery. The advantages of fresh whole blood have also been challenged. Mou and colleagues ${ }^{6}$ randomly assigned patients younger than 1 year to a pump prime with either fresh whole blood or blood reconstituted from components. They found that fresh whole blood provided no advantages in either hemostasis or other outcomes.

The story of the hemostatic agent aprotinin has been somewhat convoluted. Aprotinin is a nonspecific, competitive serine protease inhibitor. Its hemostatic actions in heart surgery include inhibition of fibrinolysis and preservation of platelet function. Aprotinin was removed from the world market in 2007 on the basis of data in adult cardiac surgery patients but without an adequate assessment of its risks and benefits in pediatric patients. It was replaced in most 
pediatric practices by one of the lysine analogs, $\varepsilon$-aminocaproic acid or tranexamic acid, the actions of which are limited to antifibrinolysis. It has been many surgeons' personal observation (mine included) that aprotinin is a far more effective hemostatic agent than the lysine analogs. The superior efficacy of aprotinin relative to the lysine analogs in pediatric patients has been borne out in several retrospective analyses. ${ }^{8-11}$ Both Health Canada in 2011 and the European Medicines Agency in 2012 elected to allow aprotinin to be used again in their jurisdictions. ${ }^{12}$ In 2012, the Nordic Pharma Group acquired from Bayer the worldwide rights (except in the United States) to aprotinin. Aprotinin is now commonly used in pediatric cardiac cases in Great Britain and Europe, but it (unfortunately) remains unavailable in the United States.

The variable availability of aprotinin has stimulated interest in other pharmacologic approaches to post-CPB coagulopathy and bleeding. One of these is recombinant activated factor VIIa (NovoSeven; Novo Nordisk, Princeton, NJ). Factor VII is approved by the US Food and Drug Administration for use in patients with hemophilia A or B with inhibitors to factor VIII or IX, and in patients with congenital factor VII deficiency. ${ }^{13}$ Off-label use of factor VII has expanded to other populations, including pediatric cardiac surgical patients. Factor VII can be used either in a prophylactic approach or as rescue therapy after other hemostatic measures have failed. Despite its increased use in pediatric cardiac surgical patients, data on the risks and benefits of factor VII in this population are limited. There has been only a single prospective, randomized, controlled trial. ${ }^{14}$ This study, carried out in Melbourne, Australia, looked at the prophylactic use of a single dose of factor VII $(40 \mu \mathrm{g} / \mathrm{kg})$ in infants (age $<1$ year). Factor VII was administered immediately after protamine. The study found no benefit to prophylactic factor VII, specifically no change in either blood loss or transfusion. ${ }^{14}$ A comprehensive review of the use of factor VII in pediatric cardiac surgery has recently been published. ${ }^{13}$ It concludes that there is no evidence to support the prophylactic or routine use of factor VII but that rescue therapy for bleeding refractory to conventional therapy may be appropriate. There remain concerns about its cost and safety, particularly for patients with prosthetic systemic-topulmonary shunts.

I recently reviewed my program's use of factor VII in pediatric patients. Factor VII was administered in the operating room after CPB only after other components (platelets, cryoprecipitate) had been administered, and standard hemostatic measures were used. During the 2-year period from 2014 to 2016, we used factor VII in a total of 66 patients. These patients comprised $13 \%$ of the pediatric heart surgery $(\mathrm{CPB})$ cases during that time. A total of 114 doses of factor VII (each dose $90 \mu \mathrm{g} / \mathrm{kg}$ ) were used in the 66 patients for an average of 1.7 doses per patient, with a range from 1 to 4 doses. Among the 66 patients, $56(85 \%)$ were infants $(<1$ year) and $34(52 \%)$ were neonates $(<1$ month). Of the 66 patients, 10 had a systemicpulmonary shunt ( 7 right ventricle to pulmonary artery, 2 central, and 1 modified Blalock-Taussig shunt), all placed as part of a Norwood operation or other complex procedure. One of these 10 patients had shunt thrombosis occur. The cost of a single dose for a 4-kg baby $(90 \mu \mathrm{g} / \mathrm{kg})$ was roughly $\$ 500$, which compared favorably with the cost of blood products and operating room time. Factor VII often produced a visible change in the operative field within 5 to 10 minutes of administration. There is clearly a need for more complete data on the use of factor VII in pediatric cardiac patients. In the future, a good source of this information may be the anesthesia module of the Society of Thoracic Surgeons Congenital Heart Surgery database.

Gottlieb and Andropoulos ${ }^{2}$ are to be commended for their topical and useful review. Coagulation management remains an important issue for pediatric cardiac care providers and for our patients. It is one of many issues that make congenital heart surgery a challenging and at times humbling field. There is no doubt that time spent in the operating room dealing with perioperative bleeding has led to the tongue-in-cheek aphorism, "If it weren't for the bleeding, congenital heart surgery would be a lot of fun."

\section{References}

1. Miller GW. King of hearts: the true story of the maverick who pioneered open heart surgery. New York: Random House; 2000.

2. Gottlieb EA, Andropoulos DB. Current and future trends in coagulation management for congenital heart surgery. J Thorac Cardiovasc Surg. 2017; $153: 1511-5$

3. Manno CS, Hedberg KW, Kim HC, Bunin GR, Nicolson S, Jobes D, et al. Comparison of the hemostatic effects of fresh whole blood, stored whole blood, and components after open heart surgery in children. Blood. 1991; 77:930-6.

4. Norwood WI Jr. Norwood procedure-how it started. Presented at: AATS/STS Congenital Heart Disease Symposium, 90th Annual Meeting of the American Association for Thoracic Surgery. May 2, 2010; Toronto.

5. Gruenwald CE, McCrindle BW, Crawford-Lean L, Holtby H, Parshuram C, Massicotte P, et al. Reconstituted fresh whole blood improves clinical outcomes compared with stored component therapy for neonates undergoing cardiopulmonary bypass for cardiac surgery: a randomized controlled trial J Thorac Cardiovasc Surg. 2008;136:1442-9.

6. Mou SS, Giroir BP, Molitor-Kirsch EA, Leonard SR, Nikaidoh H, Nizzi F, et al. Fresh whole blood versus reconstituted blood for pump priming in heart surgery in infants. N Engl J Med. 2004;351:1635-44.

7. Jobes DR, Sesok-Pizzini D, Friedman D. Reduced transfusion requirement with use of fresh whole blood in pediatric cardiac surgical procedures. Ann Thorac Surg. 2015;99:1706-11.

8. Breuer T, Martin K, Wilhelm M, Wiesner G, Schreiber C, Hess J, et al. The blood sparing effect and the safety of aprotinin compared to tranexamic acid in pediatric cardiac surgery. Eur J Cardiothorac Surg. 2009;35:167-71.

9. Wilder NS, Kavarana MN, Voepel-Lewis T, Paugh T, Lee T, Ohye RG. Efficacy and safety of aprotinin in neonatal congenital heart operations. Ann Thorac Surg. 2011;92:958-63

10. Scott JP, Costigan DJ, Hoffman GM, Simpson PM, Dasgupta M, Punzalan R, et al. Increased recombinant activated factor VII use and need for surgical reexploration following a switch from aprotinin to $\varepsilon$-aminocaproic acid in infant cardiac surgery. J Clin Anesth. 2014;26:204-11. 
11. Lin CY, Shuhaiber JH, Loyola H, Liu H, Del Nido P, DiNardo JA, et al. The safety and efficacy of antifibrinolytic therapy in neonatal cardiac surgery. PLoS One. 2015;10:e012651.

12. European Society of Anaesthesiology task force reports on place of aprotinin in clinical anaesthesia. Aprotinin: is it time to reconsider? Eur JAnaesthesiol. 2015;32:591-5.

13. Guzzetta NA, Russell IA, Williams GD. Review of the off-label use of recombinant activated factor VII in pediatric cardiac surgery patients. Anesth Analg. 2012;115:364-78.
14. Eckert H, Brizard C, Eyers R, Cochrane A, Henning R. Elective administration of low-dose recombinant activated factor VII (rFVIIa) in cardiopulmonary bypass surgery for congenital heart disease does not shorten time to chest closure or reduce blood loss and need for transfusions: a randomized, double-blind, parallel group, placebocontrolled study of rFVIIa and standard haemostatic replacement therapy versus standard haemostatic replacement therapy. Blood Coagul Fibrinolysis. 2006;17:389-95. 